\title{
Explosions and static electricity
}

\author{
Jonassen, Niels M
}

Published in:

Electrical Overstress/Electrostatic Discharge Symposium Proceedings, 1995

Link to article, DOI:

10.1109/EOSESD.1995.478301

Publication date:

1995

Document Version

Publisher's PDF, also known as Version of record

Link back to DTU Orbit

Citation (APA):

Jonassen, N. M. (1995). Explosions and static electricity. In Electrical Overstress/Electrostatic Discharge Symposium Proceedings, 1995 (pp. 331-337). IEEE. https://doi.org/10.1109/EOSESD.1995.478301

\section{General rights}

Copyright and moral rights for the publications made accessible in the public portal are retained by the authors and/or other copyright owners and it is a condition of accessing publications that users recognise and abide by the legal requirements associated with these rights.

- Users may download and print one copy of any publication from the public portal for the purpose of private study or research.

- You may not further distribute the material or use it for any profit-making activity or commercial gain

- You may freely distribute the URL identifying the publication in the public portal

If you believe that this document breaches copyright please contact us providing details, and we will remove access to the work immediately and investigate your claim. 


\title{
EXPLOSIONS AND STATIC ELECTRICITY
}

\author{
NIELS JONASSEN \\ PHYSICS DEPARTMENT, BUILDING 307 \\ TECHNICAL UNIVERSITY OF DENMARK \\ DK-2800 LYNGBY, DENMARK \\ PHONE: +45 458824 88, FAX: +45 45932766
}

\begin{abstract}
The paper deals with the problem of electrostatic discharges as causes of ignition of vapor/gas and dust/gas mixtures.

A series of examples of static-caused explosions will be discussed.

The concepts of explosion limits, the incendiveness of various discharge types and safe voltages are explained.
\end{abstract}

\section{INTRODUCTION}

Probably the most dramatic and extensive known effect of an electrostatic discharge was the serious accident at Cape Kennedy in 1964 where discharges between charged plastic sheets and the body of a space vehicle started a fire that killed three people, injured eleven others and caused damages for about $55 \mathrm{M} \$$.

But static related accidents had been known long before this.

In the fall of 1915 the US midwest states shook by an astonishing number of explosions in threshing machines.

An investigation of 94 cases revealed that in about $75 \%$ of the accidents, electrostatic charging had occurred and that in about half of all the cases other causes but electrostatic discharges could be ruled out as the ignition source. In about $30 \%$ of the cases, the machinery was totally destroyed by the explosion or the resulting fire'.

In January 1954, an explosion happened during an operation in a hospital in Århus, Denmark. The anaesthetist assisted the patient's breathing by rythmically compressing a respiration bag (of ordinary insulating rubber) hereby rubbing the bag against a metal "hair pin" inside the bag. The anaesthetic was a mixture of cyclopropane and oxygen. A discharge happened, probably from or to the "hair pin" causing an explosion. The patient did not survive 2 .

In 1.989 an operator in a Danish chemical plant was pouring resin into a mixing mill containing acetone (vapor). The resin was guided by a metal funnel resting on the opening of the mill. An explosion happened that injured the operator seriously. It turned out that neither the funnel nor the operator were properly grounded. The funnel could thus be charged by the direct contact with the resin. The operator was holding an insulating bag from which the resin was poured, and he could be "charged" by induction, and both processes could give rise to a discharge and possibly the ignition of the vapor/air mixture.

\section{CONDITIONS FOR EXPLOSIONS}

The above examples suggest that static electric problems have been around for a long time and the number of known static caused accidents is legion. On the other hand, static electric discharges do happen very frequently (in atmospheres containing vapors which may form explosive mixtures with air or other gases) without giving rise to ignitions or explosions.

The reason obviously is that most discharges do not have enough energy (or rather energy density) to start the necessary interactions between enough molecules of the vapor and the oxygen of the air. Or, maybe more precisely, that the incidental ratio between the concentrations of the vapor and the oxygen requires more energy dissipated per unit volume than can be delivered by a likely static discharge. 
EXPLOSIVE MIXTURES

Vapors and gases

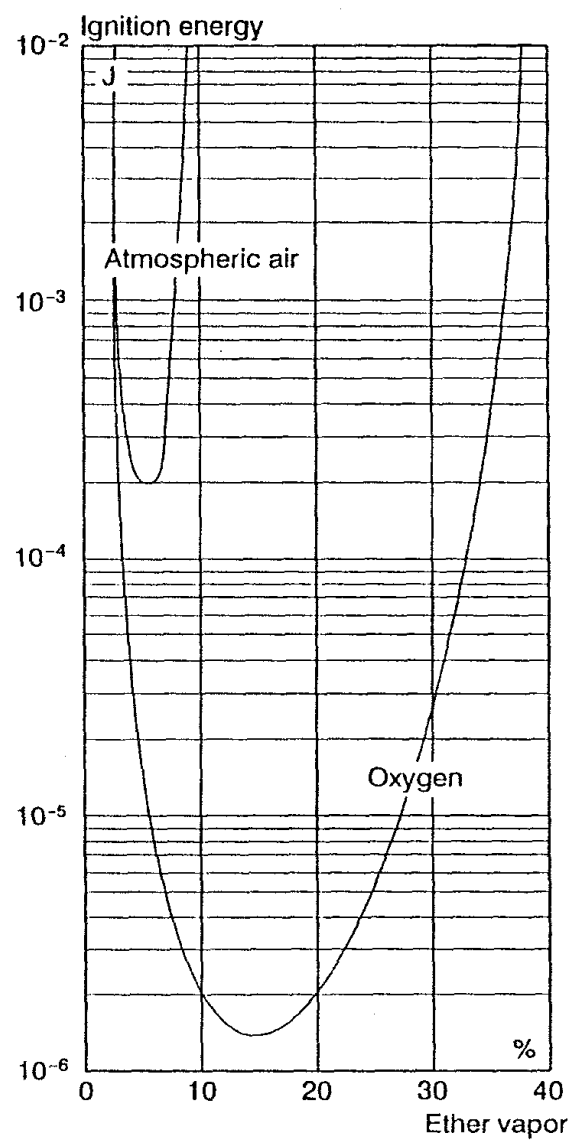

Fig. 1.

Ignition energy of ether vapor mixtures with oxygen and atmospheric air

If an atmosphere contains oxygen and vapor of an inflammable liquid a reaction (combustion) between the two components is possible if enough energy is delivered in the right way.

Some mixtures, however, are near to impossible to make react.

This is illustrated in Fig. 1 showing the ignition energy for mixtures of ether vapor and pure oxygen or atmospheric air.
It appears that it is possible to ignite a mixture of ether vapor and pure oxygen with a little more than $1 \mu \mathrm{J}$ if the concentration of ether vapor is about 16 $\%$, while it takes about $0.2 \mathrm{~mJ}$, or about 200 times more, to ignite a mixture of ether vapor and atmospheric air, and then only if the ether concentration is very close to $6 \%$.

The main reason it takes more energy to ignite a mixture with atmospheric air than with oxygen, is that it also takes energy to heat the nitrogen in the air without it participating in the combustion process, and this energy is therefore wasted.

It also appears that the necessary ignition energy of ether vapor with atmospheric air increases rapidly if the concentration deviates only slightly from the $6 \%$ minimum-energy value.

Consequently only mixtures between maybe 4 and $8 \%$ are therefore in practice explosive.

The curves shown in Fig. 1 are typical, in shape as well as in energies, for vapors of many organic compounds, cyclic as well as aliphatic, like hydrocarbons, ketons etc.

The $0.2 \mathrm{~mJ}$ value may thus be taken as a good lower energy limit for vapor/air mixtures.

The vapor concentration of the easiest ignitable mixture, however, depends upon the chemical composition of the vapor and varies from $80 \%$ (methane) to maybe $170 \%$ (heptane) or more of the stoichiometric mixture ${ }^{3}$.

Although a spark with an energy near the minimum ignition energy is potent enough to cause an explosion in mixtures within a narrow concentration range, it should be kept in mind, that if one has a container with a liquid with vapors like the ones discussed above, the vapor concentration at the surface of the liquid is probably far too high for the mixture to be explosive, and at height of maybe half a meter above the surface, the concentration may be far too low.

Therefore, somewhere in between the concentration has exactly the critical value, requiring only the minimum energy for the mixture to blow up. 


\section{Powders and gases}

It is a well known fact that explosions may happen not only in vapor/gas mixtures but also under certain conditions in clouds of dust or powders.

On the anecdotical level it can be mentioned that in the 1930's explosions in grain siloes were reported with a rate of approximately one per week in the midwestern US states.

While the (minimum) ignition energy for a vapor/gas mixture is only a question of the nature and concentrations of the vapor and the gas, as illustrated in Fig. 1, the situation is much more complicated in the case of powders.

First of all, while mixtures of vapors and gases are normally homogeneous with the vapor concentration (in closed containers) being the same throughout the whole mixture, the concentration of powder particles in a cloud may easily vary from point to point, making the determination of a minimum ignition energy very difficult.

Further, the ignition energy normally depends upon factors like the grain size of the powder involved. Generally speaking however, it takes more energy to start an explosion in a cloud of powders than in an explosive vapor/gas mixture. While minimum ignition energies for vapors in atmospheric air are lower than $1 \mathrm{~mJ}$, powders will normally require a minimum of 10 to $100 \mathrm{~mJ}$ to combust.

\section{IGNITION SOURCES}

The energy necessary to start an ignition may be delivered to the vapor/gas mixture in a variety of ways, but we will here limit the interest to electrical discharges as an ignition source, and further especially such ones caused by static electric charge accumulations.

\section{Charging parameters}

A necessary, but not sufficient, condition for a static electric discharge to be incendive is that it originates from a large, or rather concentrated, charge distribution.

Although the course of a charging process is difficult, if at all possible, to predict from the knowledge of characteristic parameters of the materials involved, certain simple rules may be formulated concerning the likelihood of encountering major charge separations under given circumstances.

\section{Solids}

Generally speaking the tendency of giving rise to high charge separation will increase with the surface resistivities of the materials involved. Often solid materials are divided into normally three (overlapping) groups after their chargebility

\section{surface resistivity}

$$
\begin{array}{cc}
\text { static materials } & >10^{14} \Omega \\
\text { astatic materials } & 10^{10}-10^{14} \Omega \\
\text { antistatic (dissipative) } & <10^{10} \Omega \\
\text { materials } &
\end{array}
$$

The division of materials into the above groups should be taken only as a rule of thumb. It is true that most measurements of chargings of solid materials show that the level of charges separated do increase with the resistivity, but definitely not in an unambiguous way.

Whille low resistive materials never charge unless the materials are separated extremely fast, there are, on the other hand, many examples of high resistive materials being brought into contact without showing any significant charges after separation.

Undoubtedly the nature of the contact play a role for the charging process.

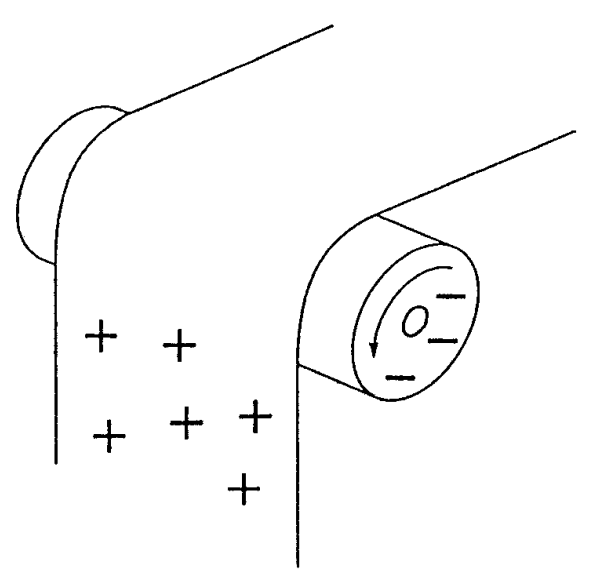

Fig. 2

Charging between conductor and non-conductor 
Normally the charges separated will be greater the more intimate the contact and friction is, and therefore smooth surfaces will often charge more than do rough ones.

When it is stated that low resistive materials do not charge, this is generally true only when both materials have low resistivity. If for instance an insulating sheet of plastic, Fig. 2, is guided by a metal roller, the sheet as well as the roller may be charged, and if the roller is not grounded, both polarities of charge may be retained after separation.

\section{Dust - powders}

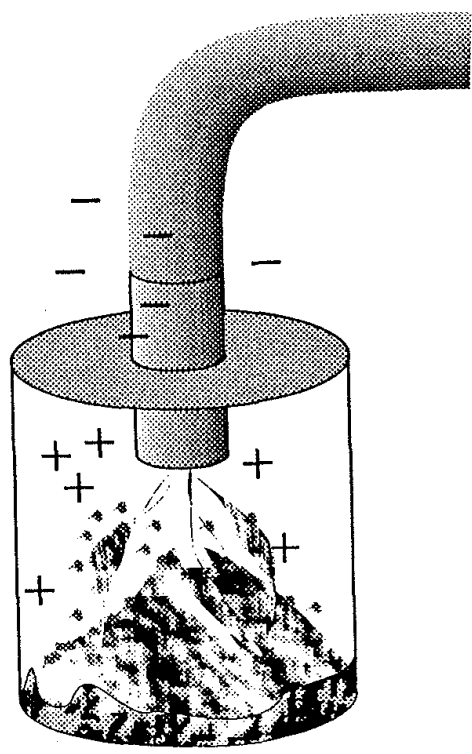

Fig. 3

Charging of a powder

Dust and powders may be charged by contact and friction between the particles, especially if the individual particles have different properties, for instance regarding size and/or material. A charging of this type may result in the particles sticking together. More common, however, are the processes where a powder is being transported through a system of tubes, Fig. 3, and the powder as a whole is being charged by the friction with the walls of the tube system.

This kind of charging may take place if either the powder or the tube or both are insulating.

The flow of charged powder can be considered as a current and it has been demonstrated that for many types of powder, the current increases with the square of the linear velocity or even stronger, and may have values of several $\mu \mathrm{A}$ for a velocity of a few meter per second.

If the powder is collected in an isolated metal container, the current will charge the container to a voltage where the unavoidable decay current is equal to the charging current.

\section{Liquids}

It has been shown that an electrical double layer exists on the surface of many liquids and that the charges in this layer can be partly separated by flow and spraying.

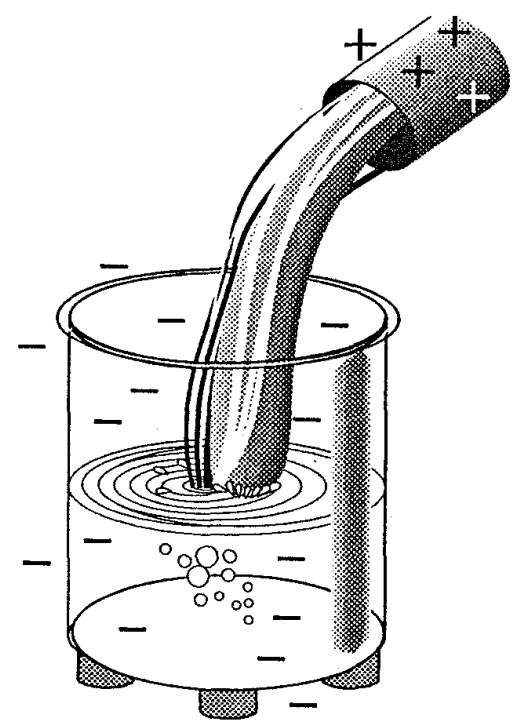

Fig. 4

Charging of a liquid by flow

If the liquid is flowing through a tube, the separated charges constitute a current to the container in which the liquid is being collected, Fig. 4 . Since the specific charge (charge per unit volume) of the liquid often depends very little on the velocity, the charging current is more or less proportional to the flow rate of the liquid.

The specific charge, in general, increases with decreasing tube diameter and flow through a filter, which can be considered as a large number of (parallel) narrow tubes, will consequently often cause chargings.

The specific charge also depends strongly on the resistivity of the liquid. 
As a rule of thumb only liquids with resistivities above $10^{7} \Omega \mathrm{m}$ will give rise to essential static chargings because of flow.

But also small amounts of additivies may change the specific charge rather drastically.

As an example, it can be mentioned that adding of water to for instance toluene, to form a disperse mixture, makes the specific charge increase considerably although the resistivity is nearly constant.

As examples of specific charges, diesel oil may have values of $10^{-6}-10^{-5} \mathrm{C} \cdot \mathrm{m}^{-3}$ and aviation gasoline about $10^{-4} \mathrm{C} \cdot \mathrm{m}^{-3}$.

While only high-resistive liquids charge by flowing, almost any liquid may give rise to charge separation by spraying. The spray may charge any insulated conducting system it hits or form space charges. The resulting fields may under special circumstances give rise to dangerous discharges, as is believed to have been the case with explosions in oiltankers during tank washing.

\section{Gases}

Finally it should be remembered that flow of pure gases, contrary to earlier popular belief, does not give rise to any charge separation.

\section{DISCHARGES}

As indicated above, a concentrated charge distribution is necessary for an electrostatic discharge, but the incendiveness depends strongly on the type of discharge.

\section{Electrical breakdown in air}

Normally, atmospheric air is considered a good insulator because the concentration of mobile charge carriers, atmospheric ions, created primarily by natural radioactive radiation, is very low.

An electric field of, say, $100,000 \mathrm{~V} \mathrm{~m}^{-1}$ will thus produce a current with a density of only a few $\mathrm{nA} \cdot \mathrm{m}^{-2}$.

If, however, the field strength exceeds a certain critical value (the breakdown field strength, $E_{b}$ ), electrons freed by the natural ionization processes will be accelerated to such high velocities and energies that they themselves will create new ions by collision in the whole region where the field strength exceeds $\mathrm{E}_{\mathrm{b}}$.

The resulting current is what we call an electrical discharge.

The value of the breakdown field strength in air at atmospheric pressure is normally given as $3 \cdot 10^{6}$ $\mathrm{V} \cdot \mathrm{m}^{-1}$

This, however, is only (almost) true for the field between plane parallel electrodes. In order to get a discharge started at a sharp point or around a thin wire the field strength at the surface has to be considerably higher.

Nevertheless, sharp points are the most likely starting places for electrical discharges. And the reason for this apparent paradox is that at a given voltage, the field strength will be higher at areas with low radius of curvature, such as points or protrusions.

The course of the resulting discharge, however, depends strongly, among other factors, upon the geometry of the body where the discharge starts and the nature of the material through which it develops.

\section{Types of discharges \\ Corona discharge}

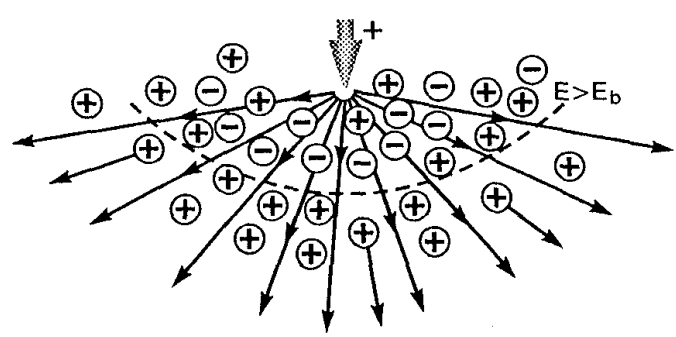

Fig. 5

Corona discharge

If a conducting electrode in the shape of a sharp point (or a thin wire) is held at a sufficiently high potential, maybe $2-20 \mathrm{kV}$, the breakdown field strength may be exceeded in a region of a few millimeters around the electrode, Fig. 5.

In this region positive and negative ions will be formed, as explained above, and ions of opposite polarity of the electrode voltage will be attracted towards the electrode, where they will be neutralized, while ions of the same polarity as that of the electrode will be repelled. Once outside the ionization region the ions move away towards grounded 
surroundings with velocities rapidly decreasing with the distance from the electrode from about 100 meter per second to maybe $1-2 \mathrm{~cm}$ per second.

This kind of discharge is called a corona or silent discharge.

If watched in the dark a bluish luminiscence may be seen in the region of ionization.

\section{Spark discharge}

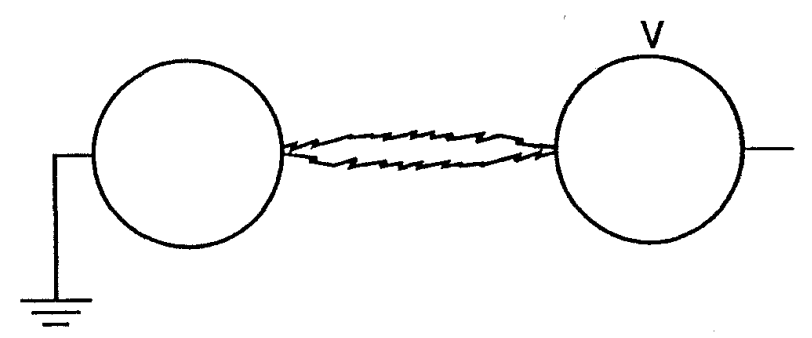

Fig. 6.

Spark discharge

The best known type of electric discharge is the spark.

Although the name is commonly used for almost any kind of charge transfer through dielectrics (including air), it ought to be reserved for the discharge between two conductors (without sharp protrusions) at different potentials.

In a spark, ionization takes place along and the charge is transferred through a narrow channel between the two conductors. In this channel, most of the energy stored in the field between the conductors will be dissipated. If the (partial) capacitance of the two conductors is $\mathrm{C}$ and their potential difference is $V$, the energy $W$ dissipated in the discharge is given by:

$$
\mathrm{W}=\frac{1}{2} C \mathrm{~V}^{2}
$$

\section{Brush discharge}

If the discharge takes place between a small electrode (radius of curvature in the order of millimeters) and ground, the discharge may be a so- called brush discharge, characterized by moving irregular luminiscent discharge paths.

It should be mentioned that discharges may also take place to or from charged insulators.

Such discharges will always be corona or brush discharges.

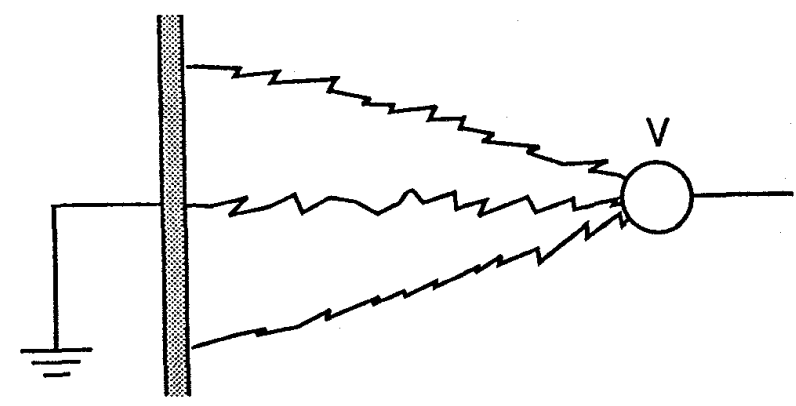

Fig. 7.

Brush discharge

\section{INCENDIVENESS OF DISCHARGES}

The ability of an electrical discharge to start a combustion or explosion depends on the energy density of the discharge.

The total energy dissipated in a corona discharge may in principle be rather high if the discharge takes the form of a continuous current.

If for instance, a discharge current of $1 \mu \mathrm{A}$ is established by a voltage of $5 \mathrm{kV}$, an energy of 5 $\mathrm{mJ}$ is dissipated in the discharge volume every second (a power of $5 \mathrm{~mW}$ ).

The density of this dissipation, in time as well as in space, however, is too small to start a combustion process in any known vapor/gas mixture. Also, a brush discharge may be maintained as a continuous current, but is in most cases, a short time event, and the energy density is much higher than in a corona discharge. It has so far not been possible to accurately measure or calculate the energy dissipated in a brush discharge, but it is estimated that total energies of about $1 \mathrm{~mJ}$ may occur under certain circumstances, which is enough 
to ignite many vapor/gas mixtures with (un)suitable mixing ratios.

It should be pointed out, however, that such high brush-energies require extremely high charge accumulations, and that consequently discharges from charged insulators normally are not incendive.

An exception to this "rule" are the so-called stemmed branch brush discharges from highly charged thin layers of insulators, backed by a grounded conductor.

The charge neutralized in such discharges and hence the energy dissipated may be very high (in the order of tenths of $\mathrm{mJ}$ ).

The Cape Kennedy accident may have been the result of such a discharge, but normally it takes carefully planned laboratory experiments to create a stemmed branch brush discharge.

The most incendive of all types of discharges is the spark discharge. The discharge volume is much smaller, and consequently the relative energy density much higher, than in a corona or brush discharge. A real spark always occurs between fairly flat regions of two conductors when the breakdown field strength is exceeded. When this happens the energy $\mathrm{W}$ dissipated is determined by the voltage $\mathrm{V}$ and by the partial capacitance $\mathrm{C}$ between the two conductors, as given by:

$$
\mathrm{W}=\frac{1}{2} \mathrm{CV}^{2}
$$

If thus, the minimum ignition energy $\mathrm{W}_{\min }$ for a given atmosphere is known, we can define an "explosion-safe" voltage $V_{\text {ex }}$ for a system with the capacitance $\mathrm{C}$ as

$$
\mathrm{V}_{\mathrm{ex}}=\sqrt{\frac{2 \mathrm{~W}_{\min }}{\mathrm{C}}}
$$

If we assume $\mathrm{W}_{\min }=0.2 \mathrm{~mJ}$ and the capacitance of the system is $\mathrm{C}=300 \mathrm{pF}$ we find

$$
V_{\text {ex }}=\sqrt{\frac{2 \cdot 0.2 \cdot 10^{-3}}{300 \cdot 10^{-12}}} \propto 1100-1200 \mathrm{~V}
$$

It should be stressed that safe-voltage levels only refer to explosion risks. When dealing with electronic ESD-problems the acceptable levels are often considerably lower.

Also, the safe-voltage levels only apply to insulated conductors, since voltage can not (or hardly ever) be meaningfully determined for an insulating material.

\section{CONCLUSION}

Electrostatic discharges may cause fires and explosions. It has, however, been demonstrated that only certain types of discharges may be incendive, and even when such discharges do occur, a series of limiting conditions have to be fullfilled in order to make the discharges become harmful.

Generally speaking, discharges from insulators are less incendive than those from and between conductors.

In the case of the potentially most harmful type of discharge, the spark, i.e. the discharge between two conductors, it is possible to define an explosionsafe upper limit of the potential difference.

\section{REFERENCES}

1. US. Department of Agriculture, Bull. 379.

2. Tidsskrift for danske sygehuse, nr. 6, 1954.

3. U.S. Bureau of Mines, Bulletin No. 520, 1953. 